Running head: A critical analysis of CAMHS policy

\title{
A critical analysis of Child and Adolescent Mental Health Services policy in England
}

Jane E.M. Callaghan ${ }^{1}$, Lisa Chiara Fellin², Fiona Warner-Gale¹,

\author{
${ }^{1}$ University of Northampton, Division of Psychology \\ ${ }^{2}$ University of East London
}

*Requests for reprints should be addressed to Jane Callaghan, University of Northampton, Boughton Green Road, Northampton, NN27AL, United Kingdom (e-mail:

jane.callaghan@northampton.ac.uk).

This article has been published by SAGE in the Journal of Clinical Child Psychology and Psychiatry, 2017 


\section{A critical analysis of Child and Adolescent Mental Health Services policy in England, 2000-2015}

\section{Abstract}

Policy in Child and Adolescent Mental Health (CAMH) in England has undergone radical changes in the last 15 years, with far reaching implications for funding models, access to services and service delivery. Using corpus analysis and critical discourse analysis, we explore how childhood, mental health, and CAMHS are constituted in 15 policy documents, 9 pre-2010, and 6 post 2010. We trace how these constructions have changed over time, and consider the practice implications of these changes. We identify how children's distress is individualised, through medicalising discourses and shifting understandings of the relationship between socioeconomic context and mental health. This is evidenced in a shift from seeing children's mental health challenges as produced by social and economic inequities, to a view that children's mental health must be addressed early to prevent future socio-economic burden. We consider the implications CAMHS policies for the relationship between children, families, mental health services and the state. The paper concludes by exploring how concepts of 'parity of esteem' and 'stigma reduction' may inadvertently exacerbate the individualisation of children's mental health.

\section{Introduction: The State of CAMHS in 2000-2015}

Radical changes to English Child and Adolescent Mental Health Services (CAMHS) and policy occurred over the last 15 years, impacting models of funding, access and service delivery. Under 'New' Labour, the 1995 document 'Together We Stand' set the tone for a wave of restructure, heralding a strong policy focus on the idea of an integrated 'Universal' CAMHS service, with an ideal of relatively seamless connections between mental health, and other services, and a focus on responsive, accessible and appropriate services for children and families. In contrast, in 2010, Conservative / Liberal coalition government policy signalled a new wave of change in CAMHS, emphasising localisation and service choice, and the integration of child and adult services. Policies are fundamental in defining what mental health is, and in shaping the landscape of care available to users of services. These policy shifts have produced waves of service restructure and recommissioning, altered funding models, and shifts in the balance of power within statutory mental health services, between health and local authorities, driven by a stated focus on increasing productivity and efficiency (Naylor et al., 2010). These policy changes reflect broader changes in government policy, with New Labour generally emphasising a larger role for the state and robust welfare system, while Conservative policy emphasises a smaller state, higher levels of localisation, and a stronger emphasis on individual responsibility, with less national spending on welfare, and parallel changes can be traced in many western countries (Hamilton, 2014). 
In policy terms, child and adolescent mental health is often framed in economic terms. It is regarded as a global public-health challenge, associated with increasing rates of mental health diagnosis and high levels of unmet mental health need (Kieling et al., 2011), and high estimated costs to the taxpayer (Olesen et al., 2012). Despite concerns that unmet mental health need produces future socioeconomic difficulty, the last British epidemiological study of mental health suggested that, in 2005 , less than $25 \%-35 \%$ of those with a diagnosable mental health condition accessed support (Green et al., 2005, cited in Department of Health, 2015). Despite being four times more likely to experience psychological problems than their wealthy counterparts, many children from low income families do not have access to mental health care (Smith et al, 2015). Knapp et al. (2015) argue that this unexplained variation could indicate poor targeting, inequality and inefficiency in the way that mental health, education and social care systems respond to emotional and behavioural difficulties.

To enable effective preventative and therapeutic services, policy frameworks should take into consideration the socio-economic and cultural contexts that shape mental health including poverty and disadvantage, and should identify strategies to tackle barriers to access to care (Fatimilehin, 2007; Ford et al., 2007; Meltzer et al., 2009). Children's wellbeing is dependent on the prevention of adverse childhood experiences (Ungar, 2015; Anda et al., 2006), and the social determinants of health (Friedli, 2009; Viner et al., 2012) which mediate family and the community's response to children in adversity. The Marmot Review of Health Inequalities indicates that, as a result of the localisation of health spending, service cuts have been most severe in regions of the UK that have also experienced the highest levels of socioeconomic deprivation (Marmot et al., 2012). This means that young people are subject to multiple layers of disadvantage, as they struggle to cope with the socioeconomic realities of 'Austerity Britain', whilst services that historically might have provided support (like CAMHS, Disability Services, etc) have been eroded by health sector cuts. Further, in neoliberal societies like the UK, mental health needs are often constructed as a socioeconomic issue, partly because of the perceived financial burden of the direct cost of intervention, and partly because of the indirect costs, associated with loss of productivity or the additional costs to society associated with unmet mental health needs (Ramon, 2008). The neoliberal construction of mental health in policy is associated with increasing 'responsibilisation' for mental health difficulties with individuals and families (Teghtsoonian, 2009), removing focus on socioeconomic factors that produce many mental health challenges.

Despite the framing of mental health as an economic imperative relevant to the UK's financial future, CAMH“ in England is generally underfunded. In January 2015, NHS England reported, in response to a parliamentary question, that f50million had been cut from CAMHS budgets from 2010-2013 (Hansard, 2015) representing a real terms cut of $6 \%$. Challenging underinvestment in mental health services, the Royal College of Psychiatrists and several leading mental health charities have called for 'parity of esteem' between mental health services and physical health, to ensure mental health services are properly funded. Associated with this discourse of 'parity of esteem' has been the further embedding of the illness metaphor in understanding children's mental 
health (Timimi, 2014), and particularly a turn to neurobiological readings of psychological distress (Rose and Abi-Rached, 2014).

This paper analyses the most influential policies published over the last 15 years, in the rapidly shifting landscape of CAMHS. We critically explore the changes in discursive construction of children and young people, of mental health and of CAMHS, and consider the implications of this for service delivery and professional practice in CAMHS.

\section{Method}

A combination of corpus analysis (wmatrix, Rayson, 2008) and critical discourse analysis (Fairclough, 2001) was used to critically explore the development of mental health policy guiding working with children and adolescents from 2000-2015. [Insert Table 1 about here]

Policy documents were divided into two time sets for analysis: 2000-2010, and 2010-2014. This enabled the tracking of policy in relation to both political and economic shifts in the UK, as May 2010 marked both a change of government and a shift to the politics of austerity. This is not explicitly to make a party political point, but rather because May 2010 represents the beginning of a clear shift in the direction of mental health policy. 'ather than 'evolving' from previous policy, the decision was to effectively start over, rendering pre 2010 policy generally obsolete. Concepts like 'Universal CAMH“' fell out of use, and the emphasis shifted from policy specific to $\mathrm{CAMH}^{\prime}$, to a more generic set of policies aimed at 'all people'. The shifts in mental health policy before and after this point in time are dramatic, reflecting both changes in government ideology, and in the socioeconomic context in which policies are produced and embedded.

The corpus analysis was conducted using wmatrix (Rayson, 2008), to identify the frequency of particular words in the policy documents, relative to their frequency in a general representative corpus of written English. This analysis identified patterns of language use, by identifying heavily used terms and phrases in the policy data set. The relative frequency data enabled a rigorous comparison of the way language was used in policy across the two time frames. It also identified important and regular features of the sets of documents, which could then be subject to further and more detailed critical discourse analysis (CDA).

Each policy document was read in full, and the main points of each were summarised. Sections of the text were sampled for more detailed discursive analysis, through two strategies. Relative frequencies from the corpus analysis were used to identify key features of the policy text, and extracts were also selected that illustrated the overall meanings of the policy identified in the summaries. CDA explores the productive and reproductive interconnections of discourses, inequalities and power relationships (Fairclough, 2001). Our concern throughout the analysis was with the productive and regulative effects of the discourses in operation 
in policy texts - how did they constitute 'the child', their relational contexts and 'mental health services', and how did these constructions shift over time, as social and economic contexts changed.

\section{Analysis - Policy Trends in CAMHS}

The analysis traces shifts in discourses of childhood, families, parenting and mental health, in English policy on CAMH, in the periods 2000- May 2010, and May 2010 - 2015. The most notable shift, observable in table 2 [INSERT TABLES 2] is the reduction in talk specifically about CAMHS, children and young people. This is to be expected given that, post 2010, policy is no longer explicitly crafted for young people and those working with them. Nonetheless, post 2010, children and young people are less explicitly referred to in the integrative policy framework than they were when policy was separated. It is not just that children and youth are less discussed, but associated systems are also less significantly in the frame; schools and families are less discussed, and primary care, which was seen as an important feature of Universal CAMHS, enabling community based service delivery, does not appear at all in the post 2010 policy word cloud. The pre 2010 documents placed an emphasis on improvement, inclusion, preventative mental health work and early intervention. The post 2010 documents are much more focused on 'mental illness' and 'mental health problems'. In post 2010 policy the language of stigma replaces a focus on 'discrimination' and 'inequalities', and there is a shift to talk about 'carers' rather than 'family'. These patterns in talk about children and mental health policy are evidenced clearly in the wmatrix word clouds figures 1 and 2. [INSERT FIGURES 1 AND 2 ABOUT HERE), and the relative frequency tables 2 and 3 . We will argue that these shifts in terminology indicate an increased individualisation, medicalization and professionalization of children's distress.

\section{Medicalising children's mental health}

The positioning of mental health as a biomedical problem is one that is clearly in evidence in policy narratives and public discourses, with an increasing equation of 'psychological distress' or 'mental health difficulties' with 'mental illness'. There is a clear 'mainstreaming' of mental health services into health more broadly, as established in the policy document No Health Without Mental Health (Department of Health, 2011). This signals both a shift to a biological framing of psychological distress as 'an illness like other illnesses', and a concomitant loss of focus on social context and concerns about inequalities in the production of psychological distress. This illness discourse removes the focus of mental health practitioners and many mental health activists away from the social conditions that are so strongly associated with mental health difficulty (poverty, poor housing, social exclusion) (Parker et al., 1995; Rogers and Pilgrim, 2014). In focusing on mental health as illness, socioeconomic conditions that shape psychological distress are removed from our analytic lens (Knapp, 
2012; Hannigan, 2013). Consequently, the impact of social policies associated with austerity, and contextual factors like school testing pressures and long hours culture become obscured as increasing rates of psychological difficulties are re-read as disorders of the brain (Rose and Abi-Rached, 2013).

The pre 2010 policy frameworks were concerned with the notion of a 'Universal CAMH"' that could meet mental health needs across a broad spectrum. Mental health for children and young people was conceptualised as a positive trait to be promoted and enhanced, with an emphasis on early intervention, and responsive and accessible services available when young people were in distress. The NSF was concerned with 'Mental health and psychological wellbeing'.
"All children and young people and their parents or carers require access to information and supportive environments to ensure that the child or young person's mental health is promoted.... Everyone in a community has a role to play in ensuring that the environment in which children are growing up promotes their mental health." (Department of Health, 2004 National Service Framework, NSF, p.10)

The opening sentence of this quote illustrates the emphasis on universality. Mental health is described here, not as a minority concern for individuals with mental 'illness', but rather is something everyone needs support in promoting. By universalizing mental health as an issue for everyone, the document implicitly works to destigmatise mental health, not by delimiting it as an individual illness, but by generalising it as an issue everyone should be concerned with. This is underscored by the CAMHS catchphrase of the early-mid 2000s, that 'mental health is everybody's business'.

The NSF document also emphasises a range of psychosocial factors in promoting positive mental health and preventing the development of mental health difficulties (in this specific extract, bullying is seen as an important social problem to tackle). It suggests the community has an important role to play in enhancing positive mental health. So, mental health is constructed here as a universal issue, and the role of the community is to support a universal entitlement to positive mental health, and to remediate mental health challenges:

\footnotetext{
"There are some children and young people who will be at greater risk of developing mental health or behavioural problems. For these children and their parents, assessment of their needs and provision of early intervention can make a significant difference." (NSF, p.45)
}

In a Universal CAMHS, the focus was not just on children with significant psychological difficulty, it was on providing a better chance for all young people through health promotion, early identification and early intervention, as well as providing expertise and service for children with longer term mental health difficulties. This is underscored by one of the key focuses of the NSF, which aimed to: 
"Tackle health inequalities, addressing the particular needs of communities, and children and their families who are likely to achieve poor outcomes" (NSF, p. 9)

The notion of 'health inequalities' functions discursively to produce health challenges as primarily linked to social underpinnings: mental health difficulties are related to health inequalities, which are seen as socioeconomic, not individual:
"Marked differences exist in the prevalence of mental disorders among children and young people in different social classes, with the most disadvantaged (social class V) being three times more likely to have a mental health problem than those from families in social class I.” (N“F, p.57)

Mental health difficulty in childhood is described as explicitly and directly linked to socioeconomic factors. Mental health is associated with disadvantage, and seen as being correlated with poverty. The social and economic are seen as a vulnerability factor contributing directly to mental health difficulties and throughout this document mental health difficulties are represented as phenomena to be understood within a social context.

The language of the post-2010 era is very different. The focus in post 2010 documents is on 'mental illness' and 'mental health problems' (see figures 1 and 2). In the pre-2010 policy documents, the term mental illness has a log likelihood of 394.71, while in the post 2010 policy documents this has significantly increased to 627.24. While there is some brief mention at various points in No Health Without Mental Health (NHWMH) (Department of Health, 2011) about health promotion and prevention, it is not a clear focus of the document in the way it was in National Service Framework (Department for Education and Skills, 2004), Every Child Matters (Department for Children Schools and Families, 2003) or Keeping Children in Mind (Department for Children Schools and Families \& Department of Health, 2010).

The shift towards a more medicalised account of mental health is signalled in the disclaimer that appears as a footnote in $\mathrm{NHWMH}$ :
“The phrase 'mental health problem' is used in this strategy as an umbrella term to describe the full range of diagnosable mental illnesses and disorders, including personality disorder... "ome people object to the use of terms such as 'mental health problems' on the grounds that they medicalise ways of thinking and feeling and do not acknowledge the many factors that can prevent people from reaching their potential. We recognise these concerns and the stigma attached to mental ill health; however, there is no universally acceptable terminology that we can use as an alternative." (NHWMH, p.7)

This discursively interesting piece of text functions to acknowledge the call for a less individualising and less medicalised account of mental health, whilst simultaneously dismissing this call. The tone of the second half of 
the footnote seems to suggest that concerns about pathologising labels are mere semantics, and that this term is as good as any other in this contested domain, trivialising substantive challenges to medicalisation.

However, this obscures the move towards medicalisation and individualisation clearly in evidence in the shift to the language of 'mental health problems', which it suggests is a generic term to cover 'mental illnesses and disorders'. Gone is the language of 'mental health is everybody's business', or the notion of mental health as a positive phenomenon to be supported. In its place is a clear emphasis on illness and disorder, constructs that function to medicalise and individualise psychological distress.

\section{Children as future hope, or future problem?: The economics of mental health}

Children's mental health and the CAMH services intended to support children and families are increasingly mainstreamed in policy frameworks into general mental health services: the notion of 'mental health at all

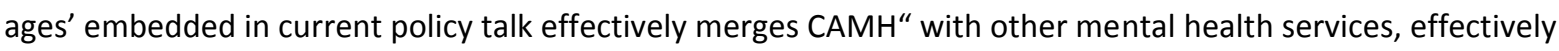
removing the previous ringfences that secured CAMHS services as specialist.

The difference in the policy frameworks is evident will be illustrated with reference to two policy documents 'Every Child Matters' (ECM, Department for Children Schools and Families, 2003) and No Health Without Mental Health:

'Children are precious. The world they must learn to inhabit is one in which they will face hazards and obstacles alongside real and growing opportunities. They are entitled not just to the sentiment of adults but a strategy that safeguards them as children and realises their potential to the very best of our ability.' (ECM, p. 3)

In this extract, children are represented as people with potential, and the responsibility of the government and community is understood as providing a safe container in which they can develop. Childhood is represented as an important and explicit policy focus in its own right to be valued as 'precious'. The language is emotive, and adults are enjoined to care and protect for them, to foster their development and to maximise their potential. Children are seen as having both rights and entitlements - they are seen as having a 'right' to realise their potential, and as entitled to a safe, supportive and nurturing environment. This discourse of entitlement enshrines a particular view of childhood and child protection within a rights based framework, naturalising a particular form of childhood - protected, and with maximisation of potential - as something all children should have access to, as a naturalised and inalienable right of childhood (Burman, 2008). This notion is further developed in the ECM document:

'Our aim is to ensure that every child has the chance to fulfil their potential by reducing levels of educational failure, ill health, substance misuse, teenage pregnancy, abuse and neglect, crime and anti-social behaviour among children and young people....' (p.6) 
One of the key aims of Every Child Matters was ensuring the children had good mental health - to be achieved by 'increasing investment in CAMHS to deliver a ten percent increase in CAMHS capacity each year for the next three years.' (p.10). The comprehensive CAMHS ideal was that diverse services work together to embed children's mental health in universal services, to train mental health workers to work in a range of agencies, and the framework suggests "services may need to be located in a range of settings, as near as possible to home in environments which are perceived as less stigmatising than traditional clinic settings, such as schools, homes and family centres" (p. 31). This approach to children's mental health positions it as in need of highly specialist support, but positions that support within a supportive community, aiming to reduce stigma through the location of psychological distress as part of the everyday, a non-clinical problem, to be taken care of in non-clinical contexts.

In contrast, consider this extract from $\mathrm{NHWMH}$ :

"This mental health outcomes strategy ... will: improve the mental health and wellbeing of the population and keep people well; and improve outcomes for people with mental health problems through high-quality services that are equally accessible to all. This is a strategy for people of all ages, and throughout this document we will use the word people to encompass infants, children, young people, working-age adults and older people." (p.5)

Like ECM, the emphasis remains on the provision of high quality and accessible services. However, children and young people are no longer framed as a special population. Rather they are incorporated in the broad term 'people'. The role of mental health services is not to enable people to reach their potential, so much as it is to 'keep the population well'. This has particular implications when set against the broad emphasis of $\mathrm{NHWMH}$ on the importance of improving the mental health of the adult population in order to reduce state dependency:

"One in ten children aged between 5 and 16 years has a mental health problem, and many continue to have mental health problems into adulthood.... Half of those with lifetime mental health problems first experience symptoms by the age of 14 , and three quarters before their mid-20s ... "ome $60 \%$ of adults living in hostels have a personality disorder. Some $90 \%$ of all prisoners are estimated to have a diagnosable mental health problem (including personality disorder) and / or a substance misuse problem."

(NHWMH, HM Government, 2011, p. 8).

The challenge of child and adolescent mental health difficulty is represented here, not so much as one of optimising personal wellbeing and potential for children's own sake, but rather as reducing risk of adult mental health difficulties. The aims of NHWMH are also more modest - "keeping people well" and "improving outcomes". There is a shift from a focus on optimisation to 'getting by'. Untreated childhood mental health 
difficulties are portrayed as resulting in adult problems like homelessness and criminality: the main concern in child mental health therefore becomes preventing the development of adult unemployment, reduced productivity and consequent economic dependency on the state. In this sense, the purpose of CAMHS are effectively reformulated in the logic of austerity, as primarily about future cost reduction, and the significance of their distress is largely understood in terms of its impact on their capacity to be productive adults in the future. Children's value, and the importance of their distress is not in what they are, but in what they may become (James and Prout, 2015).

The policy landscape is marked by a clear shift from from constructing socioeconomic difficulties as producing mental health issues, to a framing of mental health as a socioeconomic problem. This is evidenced in several examples:

\author{
"Good mental health and resilience are fundamental to our physical health, our \\ relationships, our education, our training, our work and to achieving our potential" \\ (NHWMH, p. 5). \\ "All too often ... poor mental health precipitates premature job loss. This is a waste for \\ individuals and for the economy." (Closing the Gap, 2014, p. 4)
}

"Mental illness" therefore becomes framed as a socioeconomic issue that needs to be tackled, to help keep young people 'in education' and adults 'in work'. It is seen as a barrier to productivity, something that prevents individuals from contributing to the labour force. This is a major discursive shift from the pre-2010 focus on deprivation as a cause of mental health difficulties, to a focus on mental health difficulties apparently producing socioeconomic challenge. This is extended into a representation of psychological difficulty as a 'burden' on health services:

\footnotetext{
"Mental ill health represents up to $23 \%$ of the total burden of ill health in the UK - the largest single cause of disability. Nearly $11 \%$ of England's annual secondary care health budget is spent on mental health" (NHWMH, p.10)
}

The economic language of 'burden' functions to position those with mental health difficulties as a kind of inert mass, that must be carried by others, drawing on the resources of society, and draining the economy. The post-2010 policy framework describes mental health as a disability (thus chronic) and burden to be tackled for the sake of the economy. The term 'burden' in this extract, and the use of 'resilience' as a concept in NHWMH reveals a subtle individualization of the 'problem of mental health' itself. Those with mental health difficulties are discursively divided into two categories - the unmoving 'burden', which must be borne by others, and the resilient who 'bounce back'. This language in many senses reproduces dominant discourses of strivers and skivers that characterise public debate on benefits and welfare, and that function to problematise and demonise poverty and dependency (Valentine and Harris, 2014).

In pre-2010 policy, inequality was largely framed as a vulnerability, contributing to mental health difficulty, so that mental health was understood at least partly in terms of social causes. Post 2010 mental health and social 
issues are seen as co-occurring, but social issues are no longer framed as producing distress. This is a subtle shift, and not one we wish to caricature. It is important to acknowledge that post 2010 policy does recognize the importance of addressing health inequalities. However, it is the underpinning conceptualisation of the nature of the intersection of inequalities with mental health that has shifted, and even inverted.

\section{Individualising distress}

The pre 2010 policy framework was already characterised by an emerging neoliberal agenda, focused on ideas of choice. For instance the catchphrase "No decision about me without me" underscores the shift towards an apparently patient centred approach to mental health service provision, with patients involved in decision making, treatment and service planning, with an emphasis on individual choice, participation and responsibility. For instance, in NHWMH, patients are exhorted to:

"Identify and achieve the outcomes that matter to them, including a suitable and stable place to live, educational opportunities, jobs and social contact"

This emphasis on free choice is the apotheosis of the individualising drive of the policy framework, positioning individuals as free to 'identify and achieve' better living conditions, education and jobs, and through these choices, to take responsibility for their own mental health. This framing of mental health and the circumstances that promote positive mental health as 'free choice' neatly obscures the socioeconomic factors underpinning health inequalities that make some families and individuals more vulnerable to psychological distress (Featherstone et al., 2014).

In the pre-2010 policy frameworks, families are understood as being 'in need of support'. There is a strong emphasis on understanding what makes families vulnerable, and on strengthening families to enable them to cope better. In the pre-2010 policy documents, the term 'family' appears 832 times (LL 277.47) while parents (not 'parenting') appear 739 times (LL 1580.22). In keeping with the increasingly neoliberal focus of New Labour, pre-2010 policy does already start to introduce an emphasis on early intervention, and the idea that parenting is important in preventing the development of psychological problems in children.

For example:
“Appropriate parenting styles are fundamental to caring for children's mental health.
Early attachment and bonding between parents and their babies is important and needs
to be supported.... All children and young people and their parents or carers require access to information and supportive environments to ensure that the child or young person's mental health is promoted." (National Service Framework, 2004, p. 10)

However, there is a stronger emphasis in the pre2010 policies on the family as a site of intervention and as a space in need of support. In this extract, bonding 'needs to be supported' and parents as well as children 
'require supportive environments'. In both the National Service Framework (2004) and Keeping Children in Mind (Department for Children Schools and Families \& Department of Health, 2010), the state's role in promoting mental health for children is understood as strengthening families in an active and interventionist way, using a range of tools including service level support, socioeconomic support, and at times punitive strategies (e.g. parenting orders).

"We need to increase our focus on the most critical influence on children's lives. "econd, we need to ensure necessary intervention before children reach crisis point and protect children from falling through the net" (ECM, p.3)

In this extract, the emphasis is on family level support to prevent children from experiencing difficulties. The active role of services in providing that support is captured in phrases from ECM like: "responding to the health needs of children, families and communities" and "The workforce has an important role in supporting children and families" (p.93).

In post 2010 policy, the trend is more to a framing of family as causative of 'mental illness', and of other difficulties. Vulnerable children are seen as located in "troubled" families, where poor parenting skills are understood to produce children's difficulties. There is less reference to notions of 'community', as if there is no context to the families developing vulnerability. The term 'family' itself is less frequently used in post 2010 policy - the term 'family' appears 32 times (LL 2.32), parent appears 4 times, and parenting 24 times (LL 126.68).

“A child's early experiences lay the foundations for their future life chances. Although everyone is born with their own genetic make-up, these genes interact with the family and the environment to determine a child's future health and resilience.... Children who experience negative parenting, poorquality relationships and other adversity in early life are at particular risk of a number of poor outcomes later on, including mental health problems." (Children and Young People's Health Outcomes Forum, 2012, p.4)

The work of individualising mental health is achieved by ascribing aetiology of mental health difficulties to combination of bio-genetic factors and family problems. Whilst acknowledging that some families may be 'vulnerable', and that this might be linked in some way to 'inequality', nonetheless mental health problems are constructed primarily as family problems, and particularly as problems of parenting. The social context that might challenge parents' ability to parent is reduced to parenting skills. The family as relational context is reduced to a set of 'parenting skills', and isolated from its community context. This positions parents passively as needing to be educated or trained, rather than to be supported:

\footnotetext{
"A good start in life and positive parenting promote good mental health, wellbeing and resilience to adversity throughout life. Many mental health problems start early and are associated with a number of known risk factors, including inequality. We know that employment is generally good for people's mental health and that being out of work
} 
carries an increased risk of mental health problems. Poor mental health and wellbeing are associated with a broad range of adverse outcomes, including high levels of health risk behaviours such as smoking, and alcohol and drug misuse, and experience of violence and abuse." (NHWMH, p.19)

In this example, from NHWMH, we see a subtle series of individualisations. First, the document posits that 'positive parenting' can overcome children's experiences of socioeconomic adversity, promoting 'resilience to adversity'. Whilst inequality is acknowledged as a 'risk factor', 'positive parenting' is seen as providing a kind of inoculation to its potential harm. This neatly removes the state's responsibility to provide socioeconomic solutions to problems of inequality, instead locating that duty with individual parents. This shift of responsibility from the state to individuals and families is further underscored by the suggestion that work will somehow sort out the problem of mental health difficulty, with being 'in work' offered as a solution to the risk of mental health problems. In this subtle discursive move, having acknowledged the role of inequalities in producing vulnerabilities to mental health difficulties, the policy framework shifts the burden of responsibility for resolving such inequalities away from the state and onto individuals and families. Poor mental health then becomes framed as both caused by, and producing bad choices, in the final sentence which suggests it is associated with high risk behaviours. In this way, the policy framework achieves the individualisation of distress:

"A good start in life and positive parenting are fundamental to good mental health and wellbeing and to lifelong resilience to adversity.... The social and biological influences on a child's health and brain development start even before conception and continue through pregnancy and early years of life ....Children who experience negative parenting, poor-quality relationships and other adversity in early life are at particular risk of a number of poor outcomes later on, including mental health problems. Good parent-child or carer-child relationships promote emotional, social and cognitive development, emotional resilience and healthy lifestyles." (Children and Young People's Health Outcomes Forum, 2012, p.4)

Children's wellbeing is reduced to 'health and brain development', family relationships are reduced to parenting, and a linear causal relationship is drawn between 'negative parenting' and developmental challenge, which in is understood to produce 'poor outcomes'. Thus mental health difficulties in children are constructed in policy as a consequence of bad choices, made by bad parents, with bad parenting skills. In these extracts, Margaret Thatcher's vision of British society appears to have been realised in mental health policy: "And, you know, there is no such thing as society. There are individual men and women, and there are families. And no government can do anything except through people, and people must look to themselves first." (Keay, 1987) 


\section{Future directions: Parity of esteem, stigma reduction, counselling and parenting}

\section{programmes}

It is often reported that families cannot access good quality CAMHS services when in crisis (Karanikolos, Marina, Mladovsky et al., 2013). There are numerous reasons, but one that stands out most strongly for families who are in significant difficulty and distress is the lack of a mental health diagnosis - a diagnostic label according to nosographic systems like DSM-5 and ICD10. In our analysis of the policy context, and its shifting trends, this emphasis on diagnosis, underpinned by an implicit individualisation and medicalisation of distress, in becoming more, rather than less entrenched.

For those concerned with the future of CAMHS, the concepts of stigma reduction and parity of esteem are often used to bolster calls for investment in CAMHS (Department of Health, 2015). The concept of parity of esteem was first introduced into the policy domain in Closing the Gap (Department of Health, 2014):

"We stated that mental health must have equal priority with physical health, that discrimination associated with mental health problems must end and that everyone who needs mental health care should get the right support, at the right time." (p. 4)

The construct of 'parity of esteem' appears to be a positive one for $\mathrm{CAMH}^{\prime}$, demanding that mental health problems be treated just like other health problems, arguing that the priority 'gap' in the funding of mental and physical health services must be closed. It serves as an important lever for the provision of better and more responsive mental health services. However, the fundamental assumption of the concept of parity of esteem is the notion that psychological distress is a 'medical problem like other medical problems' - a concept that might be more contentious amongst mental health professionals and academics . An uncritical deployment of the construct of parity of esteem might have unintended consequences. By conflating mental health with other health problems, we risk increasing medicalization, and further obscuring complex and intertwined family, community and socioeconomic contexts that produce and maintain distress. Further, the notion of 'parity of esteem' and 'health inequality' is perhaps not the best way to reintroduce the concept of inequality into mental health services - it shifts our emphasis onto 'service landscapes' rather than the contexts that produce distress. When this move to seeing inequality as a problem for services is coupled with the increasing individualisation of psychological difficulty, and the emphasis on parenting skills as a preventative measure in the development of mental distress, and the effect of this construct is to further individualise mental health problems. Similarly, the shift from talking about discrimination and mental health to the individualising construct of 'stigma' is perhaps not the best way to hold our social context in CAMHS.

"The stigma attached to mental ill health and the social barriers that surround it amplify its direct effects and damage the life chances of people with mental health problems." (NHWMH, p.7)

Stigma is conceptualised as an individual mark, borne by the person. It damages individuals' life chances, it makes mental 'illness' worse. The reliance in stigma campaigns on the idea that mental health problems are 
illnesses and/or disabilities further entrench individualisation and chronicization of mental health distress, rather than seeing it as a reactive and often adaptive responses to interpersonal and social difficulties. Further, many stigma campaigns focus on mental illness as a common problem that affects the people around you. For instance, Time To Change suggests " 3 of your classmates will have a mental illness", enabling the maintenance of a sense of distance between those addressed and those who experience mental health difficulties (i.e. by suggesting "your friend could have a mental health difficulty", not "you could have a mental health difficulty").

"Work is already underway to address the stigma of mental health problems in different communities particularly those who experience disproportionately high levels of mental illness, or those where the stigma of mental illness remains most significant." (Closing the Gap, p.13)

The potential perniciousness of this individualisation can be seen in this extract, where stigma is understood as being located in specific communities of vulnerable people, not in the discriminatory practices of a society characterised by inequality, and differential access to power and resources.

In these increasingly individualised discourses of mental health, barriers to engagement with mental health services for marginalised young people are understood in terms of broadening access to mental health, but not challenging the models of mental health that might be culturally inappropriate and universalising (Callaghan, 2012). Because the 'mental illness' model with its attendant notion of 'best practice' is essentially universalising, there is little space for the conceptualisation of a service that is not rooted in western models of illness and psychological disorder and their treatment.

The Government's Children and Young People's Mental Health Taskforce's report envisaged a comprehensive package of reforms intended to 'ensure no child is left struggling alone'. Their recommendations, taken further by the policy document Future in Mind (Department of Health, 2015) suggest that the current CAMH tiered system produces barriers to help, and fragmented care; they have thus introduced a new, more flexible 'needs-based' model similar to triage. Each CAMHS should have a named contact to advise schools and GPs on what to do when a child needs help, and for every school to nominate a member of staff with lead responsibility for mental health. Other recommendations include more voluntary sector 'one-stop-shops' offering support and advice to young people, more use of self-help online tools and apps to help young people manage their own mental health and know how to get help if needed, and a focus on wellbeing and positive psychology programmes. This measure places more resources in the hands of young people, earlier, which is unquestionably a positive approach. However, the commercialisation of mental health implicit in the terminology functions to underscore the presumption of the young person's individual duty to take responsibility for their mental health. Mental health becomes framed as something a skilled consumer can effectively choose their way out of, using 'one stop shops' and technology (“Depressed? There's an App for that!"). This further removes service design, delivery and professional practice from a focus on the social conditions that underpin distress. 
Future in Mind (Department of Health, 2015) emphasises the importance of early intervention to prevent the development of mental health difficulties in childhood. This is justified in terms of cost saving, as early intervention is assumed to prevent children developing more expensive mental health needs, educational difficulties, and future problems in engaging with the workforce and being productive. However, the focus of this document is on enhancing existing maternal, perinatal and early years health services, = and making parenting programmes more widely available, as well as providing new apps and digital tools for self-care. These policies prescribe self-care strategies, and parenting support to help parents manage their children's behavioural and emotional problems. Whilst more parenting support is good news, this is again set up in terms of providing parents with parenting skills. This reproduces the idea, already embedded in earlier policy frameworks, that family life is reducible to a set of skills parents can be trained in, rather than thinking about whole families with histories and contexts, needing insight and support. This functions to entrench an individualising model of mental health, and enables a further retreat of the state from providing good quality care to children and families, as, having offered 'evidence based parenting programmes', government could suggest that it has 'done its bit' for families. This is evident in the rolling out of early help programmes for 'vulnerable families', where, having done a piece of work with a family, local authorities cannot charge costs to the troubled families programme to repeat that piece of work. Whilst there is good evidence for short term gains for parents who remain in parenting programmes, there is no clear evidence that these gains are sustained over time (Barlow et al., 2010; Furlong et al., 2012). In a neoliberal context, a major aim of parenting interventions is to reduce the overall cost associated with 'vulnerable families', the lack of evidence that this has an enduring impact on children and families' outcomes does rather undermine this shift of focus away from more systemic interventions. While parenting interventions may produce positive outcomes for children in terms of reduced risk of conducted disorder and some mental health difficulties, these kinds of programmes are most effective when they target families more systemically, including both parents (Huntington and Vetere, 2015), supporting parental involvement in early education (Dawson-McClure et al., 2015), and attending to parental mental health. This suggests that focusing on parenting skills without attending the relational and social context of parenting is not an optimal strategy. The shift from family support to parenting skills in CAMHS policy signals a shift away from more complex evidence based practice. Further whilst it is clear that parenting is emotional labour, and vulnerable to stress, addressing parenting in isolation does not address sufficiently the impact of poverty on families (Yoshikawa et al., 2012). Parenting stress and compromised caregiving are linked to unstable working conditions, underemployment and income poverty, which puts a strain on wider family relationships (Yoshikawa et al., 2012; Hsueh and Yoshikawa, 2007). Young people's perception of family economic difficulties is associated with increased suicide risk, reduced quality of life and difficulties with social adjustment (Dashiff et al., 2009) while low parental socioeconomic status, family disruption and residential instability predict lifelong increases in young people's risk of depression (Gilman et al., 2003). Poverty related risks extend far beyond parenting practice and a range of socioeconomic factors intertwine with the relational context of the family to increase children's risk of mental health difficulty Intervening in one arena, without addressing the complex interplay of these varying socioeconomic factors cannot ultimately be effective. The shift in CAMHS policy to intervention in parenting skills, rather than 
providing family support the ample evidence that poverty and deprivation are the most significant health inequality predicting mental health difficulty in children and young people (Friedli, 2009; Viner et al., 2012), and that just providing parenting support and self-care apps without significant social and economic support is not genuinely effective early intervention (Ungar, 2015). This is, however, unpalatable for policymakers intent on pursuing practices of austerity and the constriction of state support for disadvantaged individuals and families.

\section{Conclusion}

This paper has explored the policy context for CAMHS, tracing changes in discourses of childhood, family, mental health and services over a 15 year period. We have explored the way that policy frames children and young people's mental health in increasingly individualising ways, and have traced the embedding of a medicalising, individualising framework that neglects social context in our understanding of both children and young people's difficulties, and the kinds of services that they need. We have suggested that terms like 'parity of esteem', whilst important in terms of securing funding for an already underfunded sector, further entrench the individualisation and biologisation of children's mental health. We suggest that a more systemic view might offer a more complex and contextualised perspective from which to understand and promote children's mental health, enabling a non-pathologising and more contextually driven understanding of children's experiences, and particularly of children's distress within their relational contexts. Further, we argue that attention to these relational contexts must always also involve attention to the socioeconomic contexts in which they are embedded, and that a truly effective CAMHS must attend to the health inequalities that so significantly predict children's distress.

\section{References}

Anda, R.F., Felitti, V.J., Bremner, J.D., Walker, J.D., Whitfield, C., Perry, B.D., Dube, S.R., Giles, W.H. (2006) The enduring effects of abuse and related adverse experiences in childhood. A convergence of evidence from neurobiology and epidemiology. European archives of psychiatry and clinical neuroscience. 256(3), 174-86.

Barlow, J., Smailagic, N., Ferriter, M., Bennett, C., Jones, H., Barlow, J., Smailagic, N., Ferriter, M., Bennett, C., Jones, H. (2010) Group-based parent-training programmes for improving emotional and behavioural adjustment in children from birth to three years old ( Review ) Group-based parenttraining programmes for improving emotional and behavioural adjustment in children from birth. . (3), 2010-2012.

Burman, E. (2008) Deconstructing Developmental Psychology. Second. Hove: Routlege.

Callaghan, J.E.M. (2012) Professional identities and communities. In C. . Walker, K. Johnson, \& L. Cunningham, eds. Community psychology and the economics of mental health: Global perspectives. Palgrave MacMillan.

Children and Young People's Health Outcomes Forum (2012) Improving Children and Young People's 
Mental Health Outcomes. London.

Dashiff, C., Dimicco, W., Myers, B., Sheppard, K. (2009) Poverty and adolescent mental health. Journal of Child and Adolescent Psychiatric Nursing. 22(1), 23-32.

Dawson-McClure, S., Calzada, E., Huang, K.-Y., Kamboukos, D., Rhule, D., Kolawole, B., Petkova, E., Brotman, L.M. (2015) A population-level approach to promoting healthy child development and school success in low-income, urban neighborhoods: Impact on parenting and child conduct problems. Prevention Science. 16, 279-290.

Department for Children Schools and Families (2003) Every child matters. London.

Department for Children Schools and Families \& Department of Health (2010) Keeping Children and Young People in Mind. London.

Department for Education and Skills (2004) National service Framework for Children, Young People and Maternity Services: Core Standards. London.

Department of Health (2014) Closing the Gap: Priorities for Essential Change in Mental Health. . (February).

Department of Health (2015) Future in mind: Promoting, protecting and improving our children and young people's mental health and wellbeing. London.

Department of Health (2011) No health without mental health. London.

Department of Health (2004) The National Service Framework for Children, Young People and Maternity Services, Standard 9. London.

Fairclough, N. (2001) Critical discourse analysis as a method in social scientific research. In Methods of critical discourse analysis. pp. 121-138.

Fatimilehin, I. (2007) Building Bridges in Liverpool: Delivering CAMHS to Black and Minority Ethnic Children and their Families. Journal of Integrated Care. 15(3), 7-16.

Featherstone, B., Morris, K., White, S. (2014) A marriage made in hell: Early intervention meets child protection. British Journal of Social Work. 44(7), 1735-1749.

Ford, T., Vostanis, P., Meltzer, H., Goodman, R. (2007) Psychiatric disorder among British children looked after by local authorities : comparison with children living in private households. British Journal of Psychiatry. 190, 319-325.

Friedli, L. (2009) Mental health, resilience and inequalities. San Francisco.

Furlong, M., Mcgilloway, S., Bywater, T., Hutchings, J., Sm, S., Donnelly, M., Furlong, M., Mcgilloway, S., Bywater, T., Hutchings, J., Smith, S.M., Donnelly, M. (2012) Behavioural and cognitive-behavioural group-based parenting programmes for early-onset conduct problems in children aged 3 to 12 years ( Review ) Behavioural and cognitive-behavioural group-based parenting programmes for early-onset conduct problems in ch. . (2), 3-5.

Gilman, S.E., Kawachi, I., Fitzmaurice, G.M., Buka, L. (2003) Socio-economic status, family disruption and residential stability in childhood: relation to onset, recurrence and remission of major depression. Psychological medicine. 33(8), 1341-1355.

Hamilton, M. (2014) The 'new social contract' and the individualisation of risk in policy. Journal of Risk Research. 17(February), 453-467.

Hannigan, B. (2013) What studies into systems tell us about mental health work and services at a time of austerity. Mental Health Nursing. 33(6), 13.

Hansard (2015) Mental Health Services: Children:Written question - 218865. Hansard, 1. [online]. 
Available from: http://www.parliament.uk/business/publications/written-questions-answersstatements/written-question/Commons/2014-12-16/218865/ [Accessed November 6, 2015].

Hsueh, J., Yoshikawa, H. (2007) Working nonstandard schedules and variable shifts in low-income families: Associations with parental psychological well-being, family functioning, and child wellbeing. Developmental Psychology. 43(3), 620-632.

Huntington, C., Vetere, A. (2015) Coparents and parenting programmes: do both parents need to attend? Journal of Family Therapy, n/a-n/a.

James, A., Prout, A. (2015) Constructing and reconstructing childhood: Contemporary issues in the sociological study of childhood. London: Routledge.

Karanikolos, Marina, Mladovsky, P., Cylus, J., Thomson, Sarah Basu, Sanjay Stuckler, David Mackenbach, Johan P. McKee, M. (2013) Financial crisis, austerity, and health in Europe. The Lancet. 9874, 1323-1331.

Keay, D. (1987) Aids, education and the year 2000! (An Interview With Margaret Thatcher). Women's Own, 8-10.

Kieling, C., Baker-Henningham, H., Belfer, M., Conti, G., Kieling, C., Ertem, I., Baker-Henningham, H., Omigbodun, O., Rohde, L.A., Srinath, S., Ulkuer, N., Rahmanem, A. (2011) Child and adolescent mental health worldwide: evidence for action. The Lancet. 378(9801), 1515.

Knapp, M. (2012) Mental health in an age of austerity. Evidence-Based Mental Health. 15(3), 13-15.

Knapp, M., Snell, T., Healey, A., Guglani, S., Evans-Lacko, S., Fernandez, J.-L., Meltzer, H., Ford, T. (2015) How do child and adolescent mental health problems influence public sector costs? Interindividual variations in a nationally representative British sample. Journal of Child Psychology and Psychiatry. 56(6), 667-676.

Marmot, M., Allen, J., Goldblatt, P., Boyce, T., McNeish, D., Grady, M., Geddes, I. (2012) Fair society, healthy lives: The Marmot Review. London.

Meltzer, H., Doos, L., Vostanis, P., Ford, T., Goodman, R. (2009) The mental health of children who witness domestic violence. Child \& Family Social Work. 14(4), 491-501.

Naylor, C., Bell, A., Health, C. for M. (2010) Mental health and the productivity challenge :improving quality and the value for money. London.

Olesen, J., Gustavsson, A., Svensson, M., Wittchen, H.U., Jönsson, B. (2012) The economic cost of brain disorders in Europe. European Journal of Neurology. 19(1), 155-162.

Parker, I., Georgaca, E., Harper, D., McLaughlin, T., Stowell-Smith, M. (1995) Deconstructing Psychopathology. London: Sage.

Ramon, S. (2008) Neoliberalism and its implications for mental health in the UK. International Journal of Law and Psychiatry. 31(2), 116-125.

Rayson, P. (2008) From key words to key semantic domains. International Journal of Corpus Linguistic. 13(4), 519-549.

Rogers, A., Pilgrim, D. (2014) A sociology of mental health and illness. Maidenhead: McGraw Hill.

Rose, N., Abi-Rached, J. (2014) Governing through the brain: Neuropolitics, neuroscience and subjectivity. Cambridge Anthropology. 32(1), 3-23.

Rose, N., Abi-Rached, J. (2013) Neuro: The new brain sciences and the management of the min. Princeton: Princeton University Press.

Teghtsoonian, K. (2009) Depression and mental health in neoliberal times: A critical analysis of policy 
and discourse. Social Science \& Medicine. 69(1), 28-35.

Timimi, S. (2014) Pathological child psychiatry and the medicalization of childhood. London: Routledge.

Ungar, M. (2015) Practitioner review: Diagnosing childhood resilience - A systemic approach to the diagnosis of adaptation in adverse social and physical ecologies. Journal of Child Psychology and Psychiatry and Allied Disciplines. 56(1), 4-17.

Valentine, G., Harris, C. (2014) Strivers vs skivers: Class prejudice and the demonisation of dependency in everyday life. Geoforum. 53, 84-92.

Viner, R.M., Ozer, E.M., Denny, S., Marmot, M., Resnick, M., Fatusi, A., Currie, C. (2012) Adolescence and the social determinants of health. The Lancet. 379(9826), 1641-1652.

Yoshikawa, H., Aber, J.L., Beardslee, W.R. (2012) The effects of poverty on the mental, emotional, and behavioral health of children and youth: implications for prevention. Am Psychol. 67(4), 272284. 